\title{
Image Processing and IoT Based Sand Theft Detection and Indication System
}

\author{
A. Ayshwarya, R. Dhanalakshmi, P. Usha Rani, S. Haripriya, R. Joshna
}

\begin{abstract}
Sand is an essential need for all kind of construction work. Due to increase in population, large amount of construction is being done. Usually sand is taken from sand mill and river beds in delta regions. When the amount of sand taken exceeds the maximum limit from the sand mill or the river beds without permission, is called "Sand theft". Due to this, the environment is affected greatly. Especially, during annual monsoon rains, due to lack of sand the dam supports lose their mechanical strength. Hence, the dam structure breaks out and we are not able to save the freshwater for upcoming summer. At present, there is no other prevention method available other than security officers. So we propose a system to monitor the amount of sand extraction in legal and illegal areas by image processing and RFID based techniques. In the legal section, when the weight of the loaded vehicle exceeds the maximum limit set by the government, then the toll mechanism will not operate and the automatic buzzer alert message will be implemented. In the illegal section, captured vehicle's image is processed and the collected data will be updated in IOT. Hence the particular authorized person can view the status of sand theft.
\end{abstract}

Keywords: RFID, UART, IOT.

\section{INTRODUCTION}

$\mathrm{U}$ sually sand is taken from sand mill and river beds in delta regions. When the amount of sand taken exceeds the maximum limit from the sand mill or the river bedwithout permission, is called "Sand theft". Sand theft causes threat to dams, bridges and river banks. It also causes river bank erosion. It affects the groundwater system and causes destruction of aquatic habitat. These days only security officers are present to monitor the amount of sand extracted from the river bed. Usually, the trucks leave the tollgate after they are loaded. There is no weighing system used to check the amount of sand loaded by the trucks.

Revised Manuscript Received on November 27, 2019.

* Correspondence Author

A. Ayshwarya, Programme Analyst Trainee in Cognizant Technology Solutions Pvt Ltd.

R. Dhanalakshmi, Assistant Professor in Electrical and Electronics Engineering Department, R.M.D Engineering College, Chennai, India.

Dr. P.Usha Rani, M.E, Ph.D, EEE Department, R.M.D.E.C, Chennai- 206,

Senior Member IEEE, pusharani71@yahoo.com
There is no system till now for detecting sand mining theft. Also, sand is taken illegally from other places apart from reserved areas without any restrictions. At present there is no monitoring system to detect the intrusion of vehicle in restricted areas. So we propose a smart system to monitor sand mining in places like empty rivers, empty lands etc through IOT.

\section{LITERATURE SURVEY}

[1]Illegal mining is a major contributor to casualties in Underground mining. Hence, a DInSAR - based illegalmining detection system (DIMDS) is done. And proved to be effective in detecting illegal mines. [2] AUV is proposed in obstacle detection method for the avoidance sonar of underwater mine for emergency rescue with an echo detection method. Since the wall of mine tunnel might not be straight, hence an extended Hough Transform is proposed. [3] Based on RFID with data-mining technology, human access detection is done by using passive RFID tag's. [4] Selfoptimizing RFID system, adapts both transmission frequency and power of the RFID reader which can be applied for robust communication with low energy consumption. [5] For faster data transfer rate and wide range, passive ultra-high frequency (UHF) RFID tags were implemented.

\section{VEHICLE SECTION}

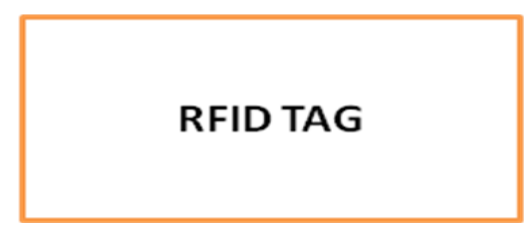




\section{BLOCK DIAGRAM}

\section{MINE SECTION:}

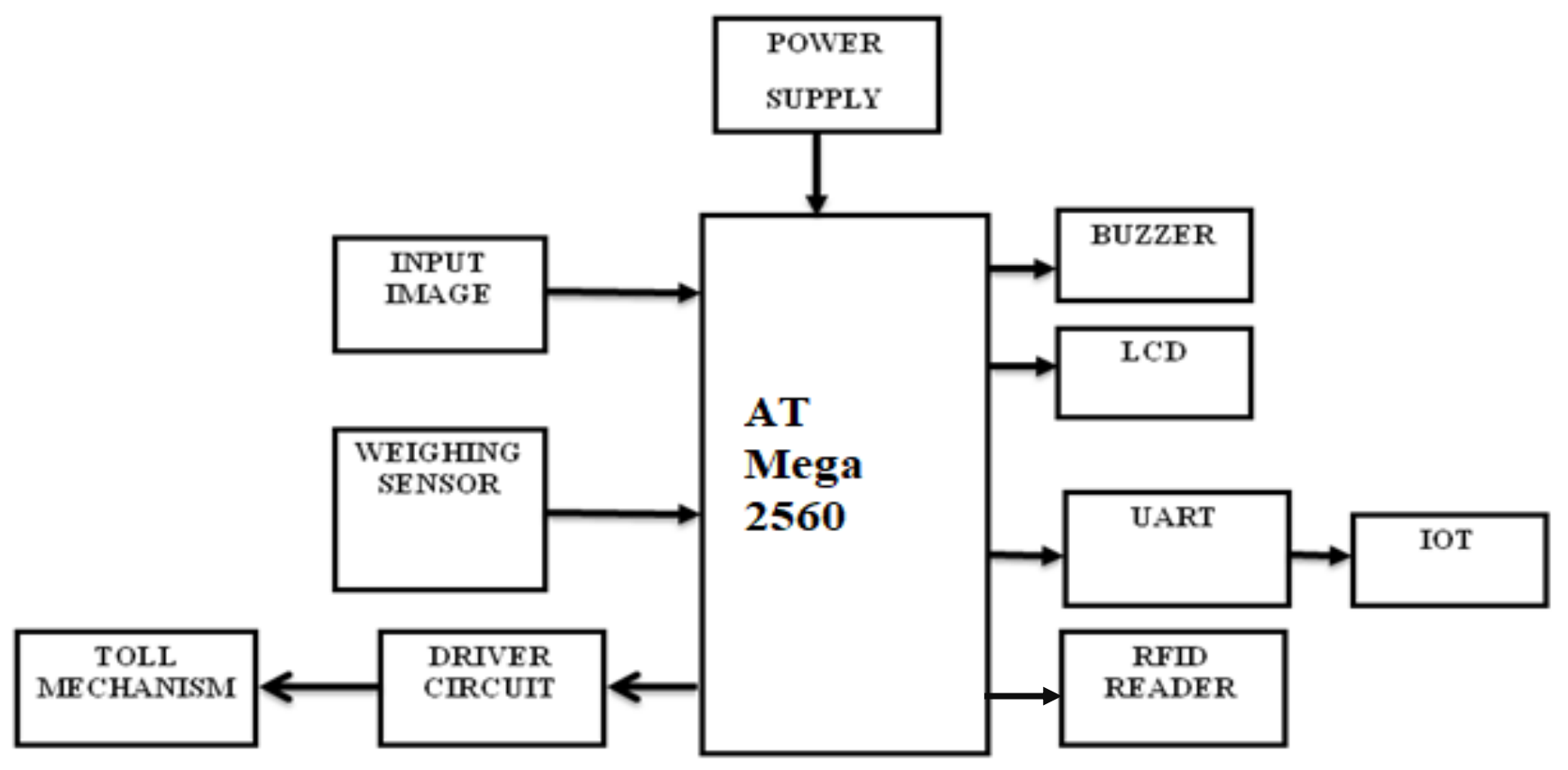

Fig.1

\section{MONITORING SECTION}

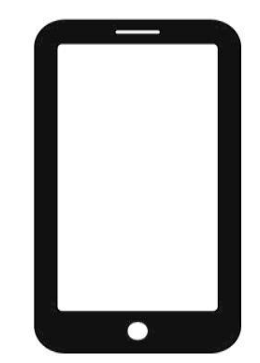

Fig. 2

The ATMega2560 controller is employed in the above system. In legal section, the RFID tag is fixed on the vehicle, which is unique for each and every vehicle. The RFID tag will possess the details of the vehicle. The RFID Reader will read the RFID tag and get the corresponding information of the vehicle. The input from load sensors controls the driver circuit of tollgate through the microcontroller. If loaded vehicle's weight is more than the maximum limit, tollgate will not open up and alert the official using buzzer. All the entry and exit details, the empty and loaded vehicle along with date and time is updated to IOT. In illegal section, once the image is sensed by camera, the microcontroller transmits the details using UART to IOT. The details along with date and time of illegal entry of vehicle is updated to IOT.

\section{Proposed SysteM}

The proposed system consists of a two set of systems, the legal system and the illegal system. In legal system the particular vehicle is allowed to mine sand in an area. The vehicle's details are constantly monitored whenever they enter such area. The vehicle's details are gathered using an active RFID tag attached to every vehicle passing through that area. The RFID reader is placed in the toll gate area where the vehicle enters and exits. During exit time the vehicle can carry excess sands than the permitted level. The weight of the vehicle by using load sensor can be checked. If it is too high then the toll mechanism is not operated and also the buzzer will indicate. Along with this, an update is provided to the server using IOT when such event is detected. In places where sand mining is restricted, an image processing based sand mining detection is carried out. This is detected using image processing technique. When a truck is detected in illegal areas where sand mining is detected, an update is provided to the server using IOT. 


\section{ATMEGA 2560 CONTROLLER :}

In order to use of above controller, an Integrated Development Environment (IDE) is required for programming the controller. Arduino IDE has many versions. Recommended is $1.0 \mathrm{v}$ which can be downloaded and installed. After the installation of IDE, the Arduino coding environment appears as in figure 3.

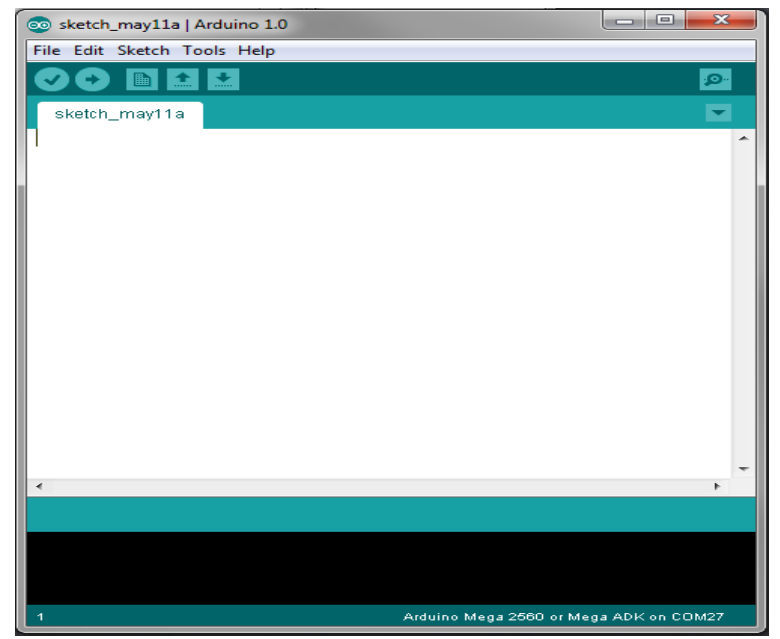

Fig. 3

\section{FEATURES OF CONTROLLER:}

Operating Voltage: 5V Input Voltage (recommended) 7-12V Digital I/O Pins: 54 (of which 14 provide PWM output) Analog Input Pins: 16

DC Current per I/O Pin: $40 \mathrm{~mA}$

DC Current for 3.3V Pin: $50 \mathrm{~mA}$

Flash Memory: $256 \mathrm{~KB}$ (Including 8kb for bootloader) SRAM: 8 KB, EEPROM: 4 KB, Clock Speed: $16 \mathrm{MHz}$

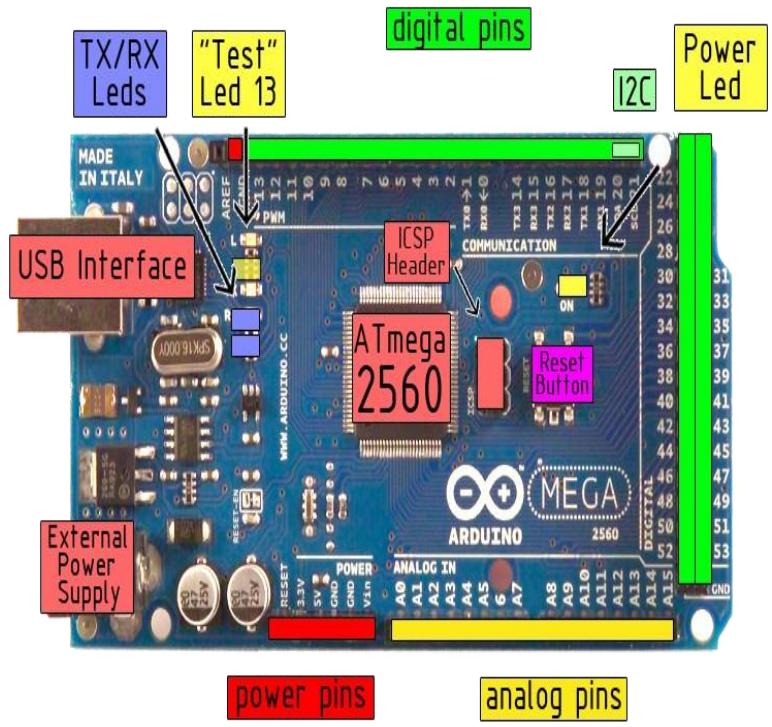

Fig. 4

\section{SIMULATION RESULTS}

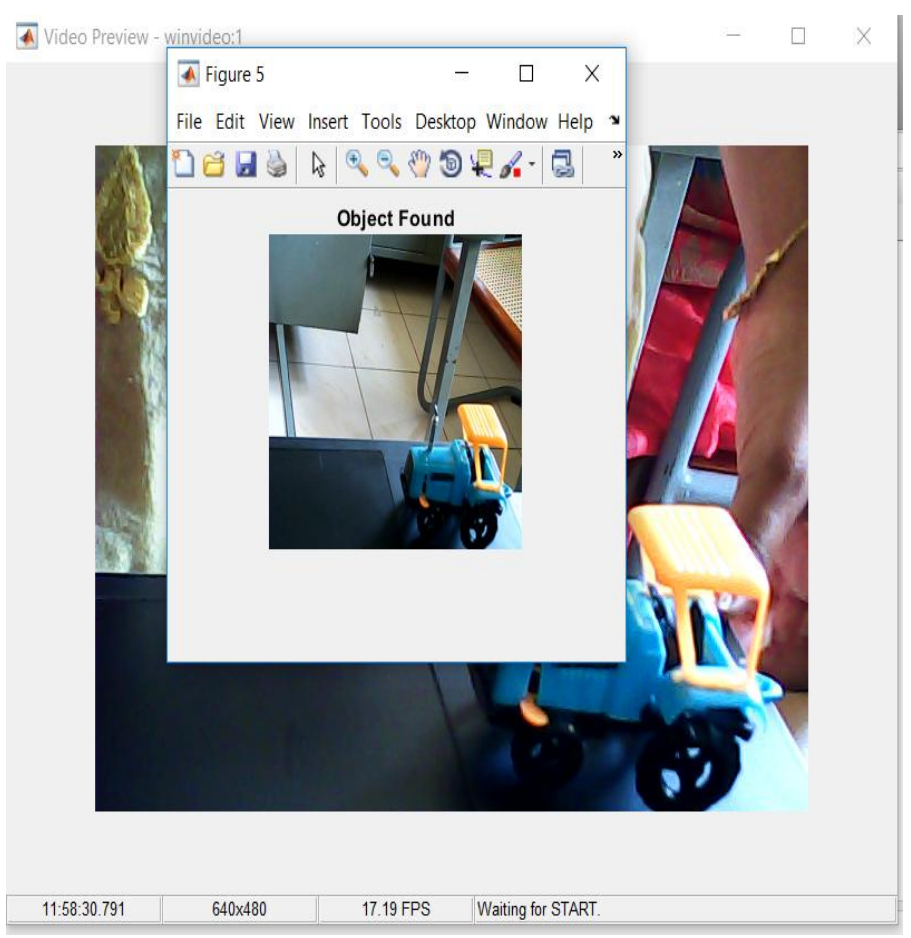

Total Sensors: 5
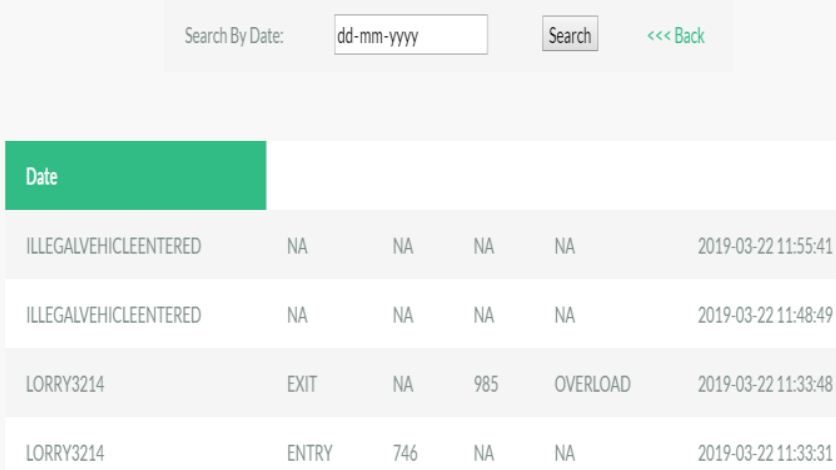

Fig. 5

The figures (Fig. 5) are result of the proposed system. The former figure shows the image of vehicle entered in illegal areas. At that instant, the image of vehicle along with date and time is updated to IOT. Thus the officer on the monitoring side gets the message immediately. In the restricted areas, when a vehicle enters its details are read from its unique RFID tag. The empty vehicle is weighed. Along with the details, the weight of unloaded vehicle is also updated to IOT. While the same vehicle exits, the above process occurs again. If weight of loaded vehicle is more than the maximum limit, a buzzer sound is made. 


\section{Image Processing and IoT Based Sand Theft Detection and Indication System}

\section{HARDWARE RESUlTS}

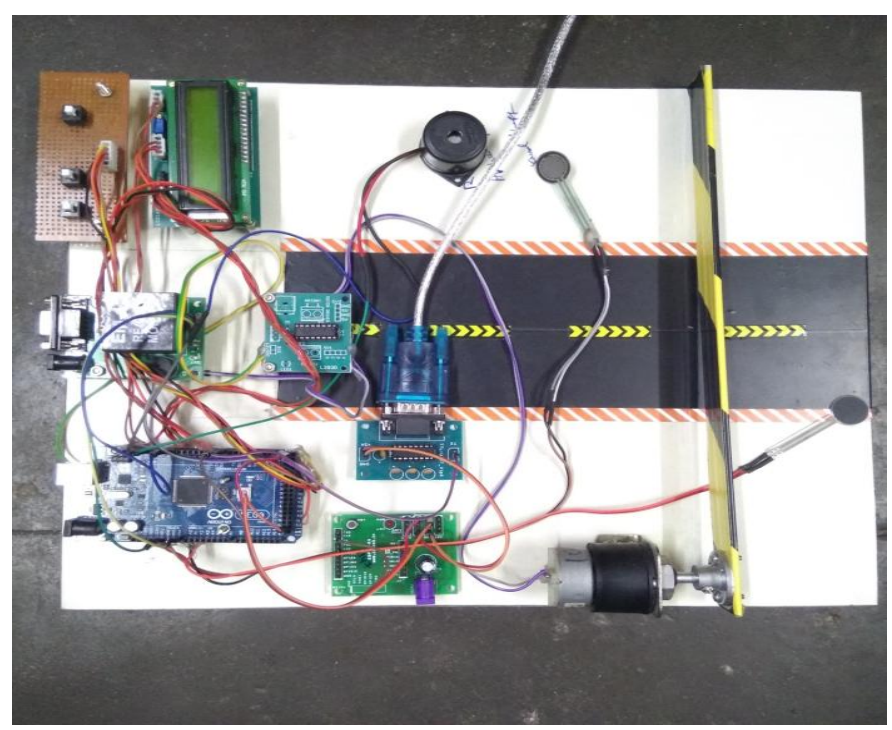

Fig. 6

The above picture depicts the hardware implementation of the idea. The directions on the road shows the entry direction of any vehicle. As the vehicle enter the RF wave range, RFID tag is read. Thus, details of vehicle is obtained. The sensor before toll is called to be entry side sensor. It weighs the unloaded vehicle. Simultaneously, both the details of the vehicle and the unloaded weight is displayed and updated through IOT. Similarly, while vehicle exits, the sensor after the toll weighs the vehicle and updates to IOT. If the weight of loaded vehicle is more than maximum limit, toll will not open up and buzzer makes sound. The toll mechanism is implemented using a $12 \mathrm{~V}$ stepper motor. The stepper motor is also called as digital motor as it understands binary inputs. This motor is driven using L293D driver circuit. Thus, the ATMega2560 controller controlls all the above process. The above process is for government approved areas for sand mining. On the other hand, for illegal mining section, a camera is set to detect any vehicle intrusion. When camera detects, a signal is sent to the controller. The controller in turn makes alert the security officer by indicating illegal vehicle entry. The below figure is a record of working model of the hardware system implemented.

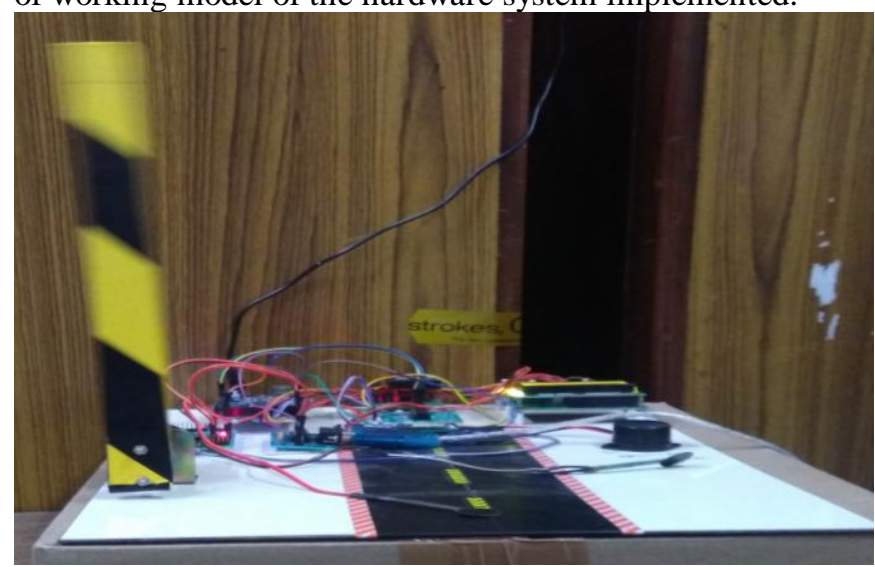

Fig. 7

\section{ConClusion}

In this project, we have proposed a solution for a social issue, "Sand theft". It is a serious problem which causes severe damage to the environment and deteriorates the dam structures. Hence we have proposed a system where the load sensor is used to weigh the amount of sand loaded by the vehicle and if the loaded weight exceeds the maximum limit, then the concerned officer will be automatically alerted about the situation through IOT and buzzer. The toll mechanism will not operate. In illegal section, when the truck enters the unreserved area, the details of the vehicle are captured through image processing technique using MATLAB. Finally, the details are updated to IOT through UART. Hence degradation of rivers and salt water intrusion from nearby seas due to sand theft can be prevented.

\section{REFERENCES}

[1] Zhe Hu; Linlin Ge; XiaOJing Li; Kui Zhang; Li Zhang, AN UNDERGROUND-MINING DETECTION SYSTEM BASED ON DINSAR. IEEE TRANSACTIONS ON GEOSCIENCE AND REMOTE SENSING(Volume: 51, ISSUE: 1, JAN. 2013 )

[2]Liu Jia, Zhang Qia, Xu Fen, Jiang Lijun, Obstacle detection method for underwater mine emergency rescue AUV. Frontiers of Sensors Technologies(ICFST), 2017 2nd International Conference on 16th April 2017.

[3]Stefan Windman, Oliver Niggeman, Holg Ruwe, Friedrich Becker, Design of a Passive Multi-Tag RFID Hospital Entry/Exit Detection System based on Data Mining Method. Sensing, Diagnostics, Prognotics and Control(SDPC), 2017 International Conference on 18 Aug.

[4] Zhe Hu, Linlin Ge, Xiaojing Li, Kui Zhang., A Novel Self-Configuration Method for RFID Systems in Industrial Production Environments. Emerging Technologies and Factory Automation(ETFA),2017 22nd IEEE Interrnational Conference on15 Sep 2017.

[5]Sheng Huang, Oon Peen Gan, Sethu jose, Mo Li., Localization for Industrial WareHouse Storage Rack Using passive UHF RFID System. . Emerging Technologies and Factory Automation(ETFA),2017 22nd IEEE Interrnational Conference on15 Sep 2017.

[6] W.H.W. Mahmood, et al., Maintenance management system for upstream operations in oil and gas industry: a case study. International Journal of Industrial and Systems Engineering, 2011. 9(3): p. 317-29.

[7] P.K. Dey, Decision support system for inspection and maintenance: A case study of oil pipelines. IEEE Transactions on Engineering Management, 2004. 51(1): p. 47-56

[8] J. Leng, P. Jiang and K. Ding, Implementing of a three-phase integrated decision support model for parts machining outsourcing. International Journal of Production Research, 2014. 52(12): p. 3614-3636.

[9] H. Meier, R. Roy and G. Seliger, Industrial Product-Service Systems - IPS2. 2010. p. $607-627$.

[10] G.V.A., Vasanthaet al., A review of product-service systems design methodologies. Journal of Engineering Design, 2012. 23(9): p. 635-659.

[11] Y. Geum and Y. Park, Designing the sustainable product-service integration: a product-service blueprint approach. Journal of Cleaner Production, 2011. 19(14): p. 1601-1614.

\section{AUTHORS PROFILE}

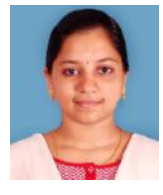

A.Ayshwarya, a Programme Analyst Trainee in Cognizant Technology Solutions Pvt Ltd. She graduated as Electrical and Electronics Engineer from R.M.D Engineering College, Anna University, Chennai, India. She has knowledge on few Embedded Technology as offered by C-DAC for Wipro Embedded COE in R.M.D. Engineering College. She is a Life member of Indian Society for Technical Education. 
R. Dhanalakshmi Assistant Professor in Electrical and Electronics Engineering Department, R.M.D Engineering College, Chennai, India. She received her B.E. degree in Electrical \& Electronics Engineering from Aalim Muhammed Salegh College of Engineering, Anna University, Chennai, India. M.E. degree in Power Electronics and Drives from Sri Venkateswara College of Engineering, Anna University, Chennai, India and pursuing Ph.D in the area of Power Electronics and Drives from Anna University, Chennai, India. She has 12 years of teaching experience. Her research interests include battery charger, DC-DC converters and SMPS. She is a Life member of Indian Society for Technical Education.

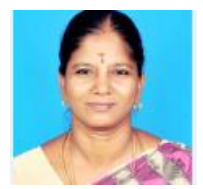

P.Usha Rani is Professor in Electrical and Electronics Engineering Department, R.M.D Engineering College, Chennai, India. She received her B.E. degree in Electrical \& Electronics Engineering from the Government College of Technology, Coimbatore, India, M.E. degree in Power Systems from College of Engineering, Anna University, Chennai, India and Ph.D in the area of Power Electronics and Drives from Anna University, Chennai, India. She has published over 57 technical papers in international and national journals / conferences proceedings (IEEE Xplore-7). She has 22 1/2 years of teaching experience. Her earlier industrial experience 4 years was with Chemin Controls, Pondicherry, India. Her research interests on application of power electronics to power quality problems and FACTS. She is a Senior member of IEEE and Life member of Indian Society for Technical Education. 